\title{
Ensaio sobre o conceito 'dignidade da pessoa humana': um juízo legítimo ou um legitimador de juízes?
}

\section{Essay about the concept of dignity of the human person: a legitimate judgment or a legitimating judges?}

\author{
Pablo Ricardo de Lima Falcão ${ }^{1}$ \\ Antônio Lopes de Almeida Neto ${ }^{2}$
}

\begin{abstract}
RESUMO
A dignidade da pessoa humana é um dos conceitos dogmáticos centrais mediante o qual os juristas articulam a legislação internacional com os ordenamentos jurídicos nacionais. Muitas fontes do direito se baseiam e até se erigem neste princípio valorativo. Nessa perspectiva, surgiu a necessidade de fazer um ensaio sobre o princípio da dignidade da pessoa humana enquanto lugar comum argumentativo no ambiente forense. A abordagem utilizada foi de caráter qualitativo. O método preponderante foi o dedutivo. A pesquisa é exploratória e possui duas técnicas de coleta de dados: bibliográfica e a documental. A técnica de análise de dados é a análise retórica, mais especificamente a metódica desestruturante do direito. Os resultados qualitativos obtidos foram a descrição da difícil fixação ontológica do significante investigado e a trivialidade do topos "dignidade da pessoa humana" no direito brasileiro.
\end{abstract}

\section{PALAVRAS-CHAVE:}

Hermenêutica Jurídica. Retórica. Ativismo Judicial. Dignidade da Pessoa Humana.

\section{ABSTRACT}

The dignity of human person is one of the central dogmatics concepts through which jurists articulate by which jurists articulate international law with national legal systems. Many law sources are based and even erected on this value principle. In this vision, the need arose to make an essay on the principle of the dignity of human person being as a common argumentative place in the forensic environment. The approach used was qualitative. The preponderant method

\footnotetext{
${ }^{1}$ Doutor em Direito - área de concentração em Teoria do Direito - Universidade Federal de Pernambuco (2012). Mestre em Direito - área de concentração Teoria do Direito - Universidade Federal de Pernambuco (2007). Especialista em Direito Público e Empresarial - Universidade Federal de Pernambuco (2004). Graduado em Direito pela Faculdade de Direito de Caruaru (1995). Professor Adjunto da Universidade de Pernambuco - Campus Arcoverde. Coordenador do SOPHIA - Grupo de Estudos e Pesquisas Interdisciplinares sobre Retórica e Decidibilidade Jurídica (UPE/CNPq). Integrante do grupo de pesquisa Direito do Trabalho e os dilemas da sociedade contemporânea (UPE/CNPq). Integrante do grupo de pesquisa Direito Médico. Estudos, Princípios, Discussões e Casos (UFPE/CNPq). Advogado e consultor jurídico desde o ano de 1996. Possui interesse/experiência nas áreas de: Teoria Geral do Direito, Filosofia do Direito, Retórica Forense, Biodireito.

2 Graduando em Direito - Universidade de Pernambuco - Campus Arcoverde (2015). Integrante do SOPHIA Grupo de Estudos e Pesquisas Interdisciplinares sobre Retórica e Decidibilidade Jurídica (UPE/CNPq). Pesquisador dos projetos: Pesquisa e Produção do Conhecimento sobre Gênero e Direito no Brasil e A Construção Discursiva do Biodireito. Possui interesse nas seguintes áreas: Teoria Geral do Direito, Filosofia do Direito, Gênero e Estudos Empíricos no Direito.
} 
was deductive. The research is exploratory and has two techniques of data collection: bibliographical and documentary. The technique of data analysis is rhetorical analysis, more specifically the deconstructive method of law. The qualitative results obtained were the description of the difficult ontological fixation of the investigated signifier and the triviality of the topos 'dignity of the human person' in brazilian law.

KEYWORDS:

Legal Hermeneutics. Rhetoric. Legal Ativism. Dignity of Human Person.

\section{INTRODUÇÃO}

A dignidade da pessoa humana é um dos conceitos dogmáticos centrais para se efetivar a articulação entre a legislação internacional e os ordenamentos jurídicos nacionais. Muitas fontes do direito se baseiam e até se erigem a partir deste princípio valorativo. Todavia, nos últimos anos, percebe-se uma banalização do uso dele entre os legisladores e os juristas, despertando, assim, uma curiosidade sobre seu processo retórico de significação.

Nessa perspectiva, a problemática central do presente estudo é: o princípio da dignidade da pessoa humana é apenas uma estratégia retórica para legitimar tutelas sociais ou também funciona como um topos legitimador do arbítrio de juízes ou tribunais? Por isso, escolheu-se fazer um ensaio crítico sobre o termo para tentar sanar as dúvidas acerca da possível (ou não) ontologia do conceito da dignidade humana.

O objetivo geral foi analisar se o princípio da dignidade da pessoa humana é articulado retoricamente para legitimar as tutelas sociais ou também funciona como um topos legitimador do arbítrio judicial. Dessa forma, uma visão analítica sobre o termo foi necessária para, em certa parte, relacionar a dificuldade da significação do termo com as "metodologias" hermenêuticas que estão sendo instrumentos de adequação do mesmo (termo).

A primeira parte do texto consiste na introdução dos principais pensamentos filosóficodogmáticos sobre o conceito da dignidade da pessoa humana. Assim, foi construída uma 
incursão conceitual em conjunto com uma apresentação teórica das principais correntes jurídicas (juspositivismo e jusnaturalismo) com o termo assinalado.

O segundo objetivo específico foi relatar sobre o problema da fixação ontológica do significante a partir de uma perspectiva linguística, mesmo em um lócus mais específico como a Constituição. Portanto, o marco legislativo escolhido serviu para buscar elementos concretos que agreguem ideação ao conceito de dignidade da pessoa humana.

O terceiro e último objetivo específico teve por escopo apresentar um estudo de caso de um julgado do Tribunal do Rio de Janeiro com o intuito de mostrar a utilização do topos da dignidade da pessoa humana no âmbito da prática forense. Essa última parte contou com as reflexões sobre o Neoconstitucionalismo e a Constitucionalização do Direito Civil como "metodologias" bastante difundidas no direito brasileiro.

A abordagem utilizada foi de caráter qualitativo. O método preponderante foi o dedutivo para discutir se a propagação do topos (dignidade da pessoa humana) realmente é uma panaceia para os problemas sociojurídicos. A pesquisa é exploratória e possui duas técnicas de coleta de dados: bibliográfica e o estudo de caso. A técnica de análise de dados é a análise retórica, mais especificamente a metódica desestruturante do direito (ADEODATO, 2014; GERHARDT; SILVEIRA, 2009).

O universo de pesquisa foi pensado da melhor forma para expressar o problema da fixação ontológica, por isso, a escolha da incursão conceitual e da Constituição tornaram-se subsídios de análise. Além de uma decisão judicial polêmica (caso Dully do Tribunal do Rio de Janeiro) que refletisse ao mesmo tempo a homologização do princípio da dignidade da pessoa humana e os problemas metodológicos do Neoconstitucionalismo e da Constitucionalização do Direito Civil. 


\section{UMA ANÁliSE RETóricA SOBRE A PLURIVOCIDADE SEMÂNTICA DO CONCEITO DA DIGNIDADE DA PESSOA HUMANA}

A retórica como filosofia do direito se contrapõe ao modo de filosofar ontológico desenvolvido pelos gregos, especificamente por Platão. Assim, esta filosofia não tem pretensões pela busca da verdade, mas de uma aproximação com a sabedoria, ou, a ignorância que o homem tem sobre o mundo (ADEODATO, 2014).

A humanidade está fadada ao caos advindo do mundo dos eventos ${ }^{3}$. Não existem lógicas, ordenações ou destinos traçados sobre tudo o que acontece. Isto é apenas um fruto da ideia que classifica ou racionaliza os fatos como únicos e irrepetíveis, adequando-se melhor à sua alta complexidade contextual.

Assim, a ideia de realidade não está na coisa em si, mas se constitui a partir da linguagem, o único ambiente conhecido pelo homem. Neste sentido, as pessoas desenvolvem estratégias para controlar melhor a polissemia existente na linguagem pública (FALCÃO, 2007).

Feitas estas considerações, torna-se necessário relacionar os níveis retóricos que serão trabalhados nesta pesquisa. A realidade linguística, anteriormente descrita, pode ser chamada de retórica material. Ela estuda a relação entre o homem e seu ambiente. Assim, o ambiente humano é a linguagem e não há nada de ontológico fora dela, mas tão somente ela (ADEODATO, 2010).

O segundo nível retórico dispõe de estratégias criadas pelas dogmáticas ou ciências de cada seara do conhecimento. Este nível linguístico será definido como estratégico, pois se utiliza dos métodos - retórica material - para direcionar os efeitos dos seus discursos, buscando alcançar o fim desejado (ADEODATO, 2010).

\footnotetext{
${ }^{3} \mathrm{O}$ mundo dos eventos representa a indiferença dos acontecimentos do mundo físico em relação ao ser humano, dessa forma, o azar, o acaso e a fortuna são partes da vida.
} 
O terceiro e último nível retórico é o analítico ${ }^{4}$. Neste relata-se quais são os métodos e as metodologias usadas por determinada esfera do conhecimento para que opere as relações comunicacionais. O grande desafio dessa meta-metalinguagem é encontrar uma forma adequada para se expressar, já que a própria língua é dogmática (ADEODATO, 2014).

Nesta primeira parte do trabalho, a retórica metódica (ou analítica) será eficaz para analisar a terminologia acerca do conceito da dignidade da pessoa humana, esboçando a mutabilidade de suas significações durante a história dos pensamentos que forneceram certas contribuições ao direito.

\subsection{Uma incursão filosófico-conceitual do termo dignidade da pessoa humana}

A expressão dignidade da pessoa humana é um dos conceitos mais utilizados nos ordenamentos jurídicos estatais e no Direito Internacional ${ }^{5}$. O problema acerca deste começa por sua difícil significação, pois há uma polissemia muito grande e os autores divergem quanto ao seu significado. Não se trata de um neologismo da modernidade, ele possui raízes na Roma antiga, o que dificulta ainda mais a efetivação de tal processo.

Os tratados internacionais e as constituições cada vez mais vêm aderindo à terminologia dignidade da pessoa humana ou os seus sinônimos: 'homem digno', 'vida digna' ou simplesmente 'dignidade'. Mas estes dados linguísticos, em maior ou menor intensidade, repetem a mesma postura: a de não definirem de forma clara a expressão.

Não é objetivo deste estudo significar/definir o que seja dignidade da pessoa humana. Afinal, a partir dos aportes filosóficos utilizados, não faz sentido a univocidade dos sentidos,

\footnotetext{
${ }^{4}$ A retórica não combate as contradições da natureza humana ou busca um racionalismo para alcançar a realidade. Esse campo apenas se utiliza destes fatos para saber como a humanidade desenvolve estratégias ou metodologias para superá-las ou ocultá-las (SOBOTA, 1996).

${ }^{5}$ Embora Sousa Santos aponte notas sobre um cosmopolitismo, ele também critica a ideia de universalidade nos direitos humanos construída pelos modernos. Na visão do autor, a universalidade é uma contradição à acepção de universal, pois os direitos humanos são construídos sob a égide dos valores ocidentais. Além disso, os documentos internacionais (que se intitulam universais) foram feitos sem a participação da maioria dos povos (SANTOS, 1997).
} 
pois as palavras enquanto significantes textuais devem ser tratadas como um dado de entrada para o processo de significação, de acordo com o contexto pragmático de seu uso ${ }^{6}$.

Dessa forma, a apresentação de alguns significados para o conceito é uma maneira reflexiva e aberta à discussão proposta, já que se consideraríamos um arbítrio linguístico tentar construir uma ideia de dignidade da pessoa humana que fosse capaz de abarcar um sentido assumido enquanto correto e universal.

A filosofia grega, em Platão e Aristóteles, reconhece o ser humano como algo divino, pois ele possui em sua estrutura interna a capacidade e o desenvolvimento da razão. Assim sendo, a razão não pertenceria ao mundo das aparências, mas ao mundo ideal. Ela seria responsável por definir o certo do errado, o justo do injusto e o verdadeiro do falso.

Entretanto, a dignidade na cultura grega, comparada aos contemporâneos, não é vista da mesma forma, pois para estes a comunidade é um fundamento importante. Já para os contemporâneos, a individualidade é o fundamento daquela (dignidade). Além disso, os gregos têm por paradigma a conformidade de uma determinada vida. Isto é, os gregos consideravam que havia uma natureza do homem para determinado fim, tornando-se uma sociedade altamente hierárquica e excludente. Para os contemporâneos, cada um constrói a sua existência (PELE, 2015).

Um léxico ${ }^{7}$ similar sobre a dignidade da pessoa humana está entre os romanos no sentido de hierarquia. Esta perspectiva decorrente da Roma antiga perdurou pela pré-modernidade, adaptando-se ao absolutismo, já que este valor era quantificado de acordo com o cargo ou status social de uma pessoa (FRIAS; LOPES, 2015).

\footnotetext{
${ }^{6}$ Segundo Rocha (1993), a sintaxe seria/é o primeiro nível linguístico do direito, nela há uma construção lógicolinguística da linguagem. A semântica, de forma complementar, seria/é o segundo nível linguístico, onde se formam as proposições ou os significados observando "os objetos" (a realidade). E por último, a pragmática que estuda a proferência (como se articula) da língua

${ }^{7}$ A palavra dignidade da pessoa humana é construída a partir do vocabulário romano: dignitas ou dignitacio; contudo, há um anacronismo semântico presente na etimologia da palavra, pois os romanos consideravam este significante como sinônimo de cargos sócio-políticos. A sociedade romana basicamente é instruída ao estilo estoico, onde a virtude humana estava disposta no desenvolvimento das qualidades intrínsecas de cada um, logo, era considerada hierarquizada (PELE, 2015).
} 
Outro sentido de dignidade da pessoa humana, mais próximo ao utilizado na modernidade, deriva da literatura de Tomás de Aquino ${ }^{8}$. Segundo ele, todo ser humano possui uma substância individual de natureza racional, onde o homem, independente do tempo e do espaço, a mantém invariabilidade. A racionalidade e o respeito aos seres humanos, nessa perspectiva, deveriam ser iguais ${ }^{9}$, já que todos são filhos de uma mesma entidade ${ }^{10}$ (MATTAR, 2010).

Diferente dos romanos, ao chegar à modernidade, a dignidade da pessoa humana se afasta de uma postura pragmática. Esse valor é (re) significado pelos modernos a partir de certos pressupostos ideológicos. O primeiro é a moral judaico-cristã ${ }^{11}$, onde o ser humano possui uma natureza desdobrada da imagem e da semelhança com Deus ${ }^{12}$. O segundo pressuposto está na filosofia iluminista que iguala a condição humana, afinal todos possuem a mesma característica comum: a razão.

Uma das diretrizes ideológicas principais, presente nesta incursão, leva aos momentos políticos pós Segunda Guerra Mundial, onde a angústia existencial invade a humanidade pelas tragédias e atrocidades alcançadas pelos regimes ditatoriais no começo do século XX (FRIAS; LOPES, 2015). Assim, no contexto de organizações mundiais, explorou-se o pensamento do filósofo iluminista Immanuel Kant.

\footnotetext{
${ }^{8}$ Há três grandes obras deixadas por Tomás de Aquino, "Comentário sobre as Sentenças", "Suma contra gentios" e a "Suma Teológica". Por outro lado, para os estudos sobre o direito, são também importantes dois tratados (equivalentes a capítulos de um livro): "tratado das leis"; "tratado da justiça". O primeiro relata sobre as regras da conduta humana, enquanto o segundo discute as virtudes e os vícios (principalmente a questão 57 ou de jure). É importante ressaltar que a Suma Teológica não deve ser estudada de forma fragmentada, pois muito se perderia em análise sobre o direito (VILLEY, 2005).

${ }^{9} \mathrm{O}$ cristianismo inaugura a ideia de igualdade e dignidade da pessoa humana entre os povos ocidentais. Filosofias como a de Kant, o idealismo alemão e outras são secularizações dessas inserções morais criadas pelos cristãos (FERRY; JOSEPHAGNON, 2011).

${ }^{10}$ Este é o pensamento religioso dentro do direito natural de Tomás de Aquino: o homem possui a inteligência especulativa de achar sua finalidade, o seu bem (dever-ser). Parte disso foi escrito no espírito humano pelo DeusPai, já que o homem é sua imagem e semelhança (VILLEY, 2005).

${ }^{11}$ Vale ressaltar que na filosofia grega, a sociedade romana e o cristianismo influenciam diretamente o aspecto moral do ocidente, deixando o mundo judaico em um processo indireto desta formação (FERRY; JOSEPHAGNON, 2011).

${ }^{12}$ A dignidade da pessoa humana dentro de uma concepção religiosa na Idade Média (aspectos gerais) se aproveitava da dignitashominis, ou seja, o homem deve através da sua liberdade, razão, moralidade e bondade perseguir um caminho natural até Deus e para isto deverá ser como sua imagem e semelhança: imitatio Dei (PELE, 2015).
} 
Kant (1994) trata a dignidade da pessoa humana como um imperativo categórico ${ }^{13}$ atuando acima de todos os homens. Assim, os indivíduos deverão se relacionar como um fim em si mesmo e não como um meio para outro fim. O filósofo encara a dignidade da pessoa humana como uma forma de não objetificação do indivíduo.

Este imperativo recai sobre todos os indivíduos, justamente por terem o mesmo aparato cognitivo e mesma capacidade moral ${ }^{14}$, sendo possível a unidade do raciocínio sobre a percepção deste objeto. A significação kantiana não é algo totalmente original. Suas ideias se inspiraram nos primeiros jusnaturalistas do pensamento ocidental, os estoicos.

Estes (os estóicos) entendiam que o direito e a moral estavam vinculados à natureza em volta deles. Se os astros, os animais e os elementos da natureza possuíam uma lógica organizacional, os humanos, da mesma forma, deveriam ordenar sua polis para uma melhor adequação do homem à sua naturalidade.

Aristóteles, mesmo sendo anterior aos estoicos, já pensava o ente dessa maneira. Para ele, o ser é formado em matéria e esta possui potência - vir-a-ser (devir) - para se tornar ato, então, era inexorável que o homem desabrochasse algo advindo de sua própria sua matéria (CASTRO JÚNIOR, 2011ª ; REALE; ANTISERI, 2003).

Os estoicos, posteriormente, também recepcionaram esta mesma reflexão (advinda dos pré-socráticos e de Aristóteles) sobre a relação natureza-homem. Para estes, havia uma lei natural advinda de uma imanência divina e racional, Zeus, estando acima do que era positivado pelos homens.

A ética estoica ${ }^{15}$ se confunde com o dever moral pelo dever moral, ou seja, não se faz nada por recompensas humanas ou divinas, nem também por fiscalização, mas porque deve se

\footnotetext{
${ }^{13}$ Kant menciona o imperativo categórico em sua obra a "Crítica da Razão Pura", aduzindo: "Portanto, se um juízo é pensado com rigorosa universalidade, quer dizer, de tal modo que, nenhuma exceção se admite como possível, não é derivado da experiência, mas é absolutamente válido a priori" (1994, p. 38).

${ }^{14}$ Embora tenha criado o modelo que influenciou o significado contemporâneo, ele não se confunde com o significado dado pelo filósofo. A dignidade humana expressa por Kant não é inerente ao ser humano, mas da capacidade humana de seguir condutas morais, diferenciando-se da contemporaneidade que prega uma inerência independente da qualidade moral do indivíduo. Além disso, o termo valor (werth) que o filósofo usou não era relativo a algo metafísico ou absoluto, mas econômico, assim, a dignidade era uma necessidade para a efetivação de uma lei moral e não uma proteção plena do ser humano (PELE, 2015).

${ }^{15}$ Segundo Croissant (1986), a moral, no sentido estoico, não poderia servir de utilidade, mas apenas enquanto moralidade em si ou realização própria do indivíduo.
} 
fazer, expressando, assim, a igualdade entre os homens e a dignidade de realizar moralmente o que a natureza reflete na racionalidade (FREITAS, 2011).

Outro importante pensamento que influenciou o século $\mathrm{XX}$ foi o do filósofo existencialista Sartre (MATTAR, 2010), o qual discordava de Kant e de Tomás de Aquino. Para o filósofo francês, a dignidade da pessoa humana não seria um valor inato à existência humana, mas criado pelo próprio homem, já que este possui a liberdade de construir e desconstruir as coisas.

Essa noção está centrada no fato de que a existência precede a essência. Desse modo, tudo o que existe é criado após o surgimento humano e não seria algo ontologicamente inato a ele. O existencialismo sartreano insiste que o homem se constitui, ou seja, a sua subjetividade ${ }^{16}$ é construída a partir das suas escolhas. Portanto, a proposta do filósofo está centrada em um ativismo sobre o seu futuro e a promoção de seu poder de liberdade ${ }^{17}$ (BITTAR; ALMEIDA, 2012).

Como já explicitado, não foi objetivo deste trabalho esgotar as discussões sobre a definição do conceito dignidade, mas apenas recortar historicamente algumas significações importantes ao estudo do mesmo. Dente estas, a definição mais trabalhada, hoje, no Ocidente, em relação ao termo estudado é a de Kant. Isso, contudo, não implica dizer que há uma fixação conceitual do seu conteúdo que seja livre de críticas.

\subsection{As duas faces da dignidade humana: jusnaturalista e juspositivista}

Outra incursão pensada está entre o jusnaturalismo e o juspositivismo que refletem também o topos da dignidade humana, isto é, como o este é instrumentalizado nessas diferentes teorias. Nasce, por exemplo, com as passagens de Antígona (SÓFOCLES, 2005) a diferença de significação entre um direito natural e um direito positivo, quando esta argumenta sobre o

\footnotetext{
${ }^{16}$ Alguns autores acreditam na construção da dignidade da pessoa humana como um papel individual e não estatal. Transferir a dignidade da pessoa humana ao direito objetivo e aos deveres da Administração Pública seria escravizar-se as forças externas ou torna-se coisa (res) (SOARES; CHIARA LOCCHI, 2016).

${ }^{17}$ Existem outros pensadores que contribuíram também para este conceito, como Hannah Arendt que considerou a dignidade da pessoa humana o valor-fonte que permite a criação de um espaço democrático para sustentar o desenvolvimento das potencialidades humanas (MATTAR, 2010).
} 
direito de enterrar o seu irmão a partir de uma fonte jurídico-moral (direito natural) maior do que a ordem do rei.

É também perceptível esta diferença nos mitos bíblicos, especificamente no Novo Testamento, pelo evangelista Marcos em seu capítulo 22 no versículo 21, onde Jesus diz: "Dai a César o que é de César e dai a Deus o que é de Deus" (BÍBLIA, 2015, p. 1490); separandose, novamente, um dado direito natural, superior e divino, do direito posto pelos homens.

O conceito de direito natural, como semente do jusnaturalismo, surge da tensão entre physis e nómos, ou seja, seria a separação daquilo que é decorrente da natureza e daquilo que é fruto da criação humana (CASTRO JÚNIOR. 2011a). O jusnaturalismo teria empreendido uma estratégia de fundamentação jurídica além daquelas positivadas pelos homens, mesmo assim, ela sempre necessitou do caráter dual, já que o jusnaturalismo só existiu na história ocidental ao lado do juspositivismo, entretanto, a recíproca não é verdadeira.

Em sua tradição, o jusnaturalismo, não é recepcionado pela apreensão empírica, mas é percebida abstratamente pelo ser humano como fruto ou parte da natureza que dá origem a esta ordem, seja de forma imanente ou transcendente. Para os jusnaturalistas, o ordenamento jurídico positivado seria coerente com as leis naturais presentes no universo. Outra característica importante é a sua imutabilidade, embora haja novas teorias jusnaturalistas que renunciam este aspecto tão marcante no direito natural clássico (ADEODATO, 2009).

Segundo Ferraz Júnior (2012), o direito positivo aduz a uma autoridade competente capaz de positivar normas e estas só poderão ser revogadas por outra de mesma competência. Como exemplo, o absolutismo determinava o rei como competente para legislar sobre os seus súditos, confundindo-se até mesmo com o Estado.

Na República romana, o Senado era a autoridade competente para dizer o que era o direito. Na tradição moderna, a palavra povo é inventada como um termo jurídico que se popularizou ao longo dos anos até se tornar um sinônimo de grupo grande ou população. Contudo, dentro da gramática jurídica, possui o significado de um coletivo que é regido pelo poder soberano no Estado Democrático de Direito. Assim, com a ideia moderna de lei, passa a se fazer necessário um espaço institucional no qual as decisões públicas fossem tomadas: o parlamento (STRECK, 2012). 
É comum entre os juristas uma confusão terminológica sobre o conceito de positivismo. Há o positivismo no sentido do direito posto e o positivismo como corrente científico-filosófica (JAPIASSU; MARCONDES, 1990). O primeiro vem do latim positivus, isto é, aquilo que foi instituído ou estabelecido. O segundo vem do francês positivisme, ou seja, é uma corrente epistemológica (conhecida também como fisicalismo) ${ }^{18}$ que tem como principal expoente Auguste Comte.

A dignidade da pessoa humana possui uma profunda intimidade com essa dualidade (MONSALVE; ROMÁN, 2009). Em suma, tudo o que será definido como digno dependerá da fonte axiológica utilizada. Neste caso, se a dignidade for pensada a partir de matrizes teóricas do jusnaturalismo, ela terá um viés mais ontológico. Logo, escolherá uma essência ou natureza no processo de sua significação. Caso ela seja definida por uma postura juspositivista, o conceito de dignidade se entrelaçará com o conceito de direito objetivo, sendo assim definido em cada contexto linguístico-cultural.

Embora se tenha criado uma resistência ao positivismo jurídico por causa das relativizações da "natureza humana" executadas pelos Estados Totalitários, observa-se que o direito posto é imprescindível para a criação do contexto democrático, pois sua constituição, dentro dessa dicotomia, é a única que abarca a diversidade de opiniões. Afinal, não se busca direitos exteriores ao homem, mas acredita-se que tudo é constituído pelo próprio.

A tentativa de naturalizar uma criação humana é o ato de retirar da coletividade a capacidade de tomar decisões sobre o seu destino. Reconhecer que há uma dada dignidade é efetivar uma ação retórica com um efeito prático bastante persuasivo: já que é preferível defender um direito fundamentando-o através de uma metafísica (imanente ou transcendente) a um discurso que leve em conta uma escolha ética passível de erros.

Para mais, as ideias do ontológico e do universal não fazem sentido perante as discussões humanas. Toda localidade e agrupamento de pessoas possuem uma língua própria,

\footnotetext{
${ }^{18}$ Mesmo que os dois conceitos em algum momento se interseccionem é preciso separar bem. Para isto, se amplia o conceito de positivismo/fisicalismo a partir de seus princípios básicos: o primeiro princípio básico do positivismo é que não há uma dicotomia entre ciências naturais e ciências sociais. Deste, desdobra-se o segundo princípio: as descrições e explicações das ciências naturais não se diferem do mundo social. Por último, o positivismo entende que há uma redução ou tradução dos conceitos sociais aos naturais. Dessa forma, as ciências sociais devem ter a mesma funcionalidade (métodos, técnicas, princípios) que as ciências naturais (FERRARO, 2015).
} 
na qual se desenvolvem conceitos particulares, percepções próprias e até uma cultura diferenciada. Dessa forma, a mutabilidade que recai sobre a significação do conceito de dignidade da pessoa humana é tão ampla e mutável - no espaço-tempo - que demonstra uma alta relatividade.

\section{O PROBLEMA DA FIXAÇÃO ONTOLÓGICA DA EXPRESSÃO DIGNIDADE DA PESSOA HUMANA}

Alguns problemas levantados por Adeodato (2014) ajudam a conduzir a problematização aqui apresentada. Segundo o autor, o direito passa por algumas reflexões acerca do direito subjetivo, tais como: há um direito de fundo ontológico? Ou são os seres humanos que o positivam? Se sim, quais são os seus limites éticos?

Dessa maneira, é preciso definir o que é o ontologismo e como seus desdobramentos farão parte do debate posto. Além disso, deve ser invocada a Constituição como forma de demonstrar o direcionamento à problematização da fixação em um lócus (linguístico) mais específico.

A ontologia, um tipo ideal que defende o conhecimento sobre as coisas a partir do próprio objeto de análise ${ }^{19}$, busca fixar uma definição em razão da essência do objeto contemplado (DA MAIA, 1999). Nesse sentido, o direito natural sempre se mostrou como uma ontologia material do direito.

A análise conceitual feita anteriormente sobre a noção de dignidade humana contribuiu para relacionar algumas considerações sobre o termo, a partir do espaço-tempo em que foi estruturado. Contudo, a significação dinâmica da expressão - dignidade da pessoa humana induz a outras questões quando se trata da tentativa de sua fixação ontológica.

\footnotetext{
${ }^{19}$ Neste sentido, concorda Chauí (2011), já que ela coloca a filosofia como a busca pela verdade.
} 
O fundamento teórico desta pesquisa se dá em oposição aos ontologismos ${ }^{20}$. Por outro lado, a ontologia também não poderá ser rechaçada por completo. Afinal, todas as abordagens epistemológicas sobre um dado objeto possuem, ao menos, um mínimo semântico que faz o ser humano, através do controle público da linguagem, identificar o que aquilo é (mesmo não o definindo da mesma forma todas às vezes).

Eis que, para o presente estudo, o âmbito linguístico não é universal - porque as línguas são fechadas em si mesmas -, mas também não compartilham de um solipsismo - pois a linguagem não é idiossincrática, já que precisa de mais de um comunicante para poder ser expressa.

Acredita-se, assim, que o problema da fixação irá se instalar linguisticamente quando a demanda de certo grupo for altamente complexa, causando uma crise, onde as pessoas não conseguirão se entender (metaforicamente falando). Eis que o direito moderno para resolver quadros desta natureza, instaura um contexto de progressivo esvaziamento de conteúdos axiológicos ${ }^{21}$, os quais tradicionalmente forneciam as bases consensuais do direito positivo.

Em outras palavras, a modernidade tem se caracterizado pelo abandono do ontologismo em prol de um nominalismo semântico e de um positivismo funcionalista (ADEODATO, 2009). Mesmo assim, acreditamos que a complexidade social é alta e tem gerado crises de legitimidade ${ }^{22}$.

\subsection{Dignidade da pessoa humana: um dado linguístico}

Conceitos que possuíam a aparência de unívocos, cada vez mais, vão sendo substituídos (porosidade), tornando o processo de comunicação cada vez mais confuso. Em se tratando do

\footnotetext{
${ }^{20}$ Dados, a priori, considerados axiomas sobre a natureza de algo, não podendo este objeto ser observado ou definido de outro modo (DA MAIA, 1999)

${ }^{21}$ A dogmatização do direito permitiu a construção de postulados formais para manter uma segurança jurídica, neste sentido, o aumento do foco no procedimento é inexorável, já que para legitimar algo no direito moderno precisa-se da validade formal, independente do conteúdo ético (no primeiro plano) (ADEODATO, 2010)

${ }^{22}$ Os retóricos analíticos não acreditam no sentido de regularidade como algo permanente e universal, mas um padrão constituído pelo observador que se encontra dentro do sistema (SOBOTA, 1996).
} 
sistema jurídico não é diferente, a gramática utilizada nesse campo, mesmo sendo mais restrita, sofre os mesmos problemas da linguagem natural.

Embora haja o acréscimo da dogmática jurídica (tecnologia do direito) que opera na redução dessa complexidade linguística, a relatividade e a pluralidade inerentes ao período histórico-cultural presente (pós-modernidade) ${ }^{23}$, vai rompendo as amarras da segurança jurídica e da legitimidade (o valor de justo) na sociedade (BITTAR, 2009).

O direito enfrenta os riscos das suas decisões e inaugura uma crise em seu sistema, perdendo confiança diante daqueles que provocam o Judiciário, seja no âmbito nacional ou internacional. Nesse contexto, o termo dignidade da pessoa humana aparece como uma panaceia sintático-semântica por ser um dado linguístico de grande amplitude significativa nos tribunais.

Essa resolução de alguns problemas jurídicos através da generalização do conceito da dignidade da pessoa humana padece de alguns problemas de natureza linguística. O conceito, por exemplo, não descreve a realidade, porque é necessário definir o conceito para tentar descrever a realidade. Assim, não se conhece a realidade pelos conceitos, pois a única realidade possível de conhecer é a linguagem (FERRAZ JÚNIOR, 2015).

Além disso, os conceitos possuem compreensão e extensão (ADEODATO, 2009). A compreensão é o rigor linguístico que um conceito tem para adotar algum objeto a ele mesmo, já a extensão é quantidade de objetos que estão sob o mesmo conceito. Eles são inversamente proporcionais.

Dessa forma, o conceito de dignidade da pessoa humana é mais um dado que possui baixa compreensão e alta extensão, embaraçando até os interlocutores da mensagem - dentro da comunicação - sobre o seu significado.

Em se tratando da utilização dos termos pelo legislativo brasileiro, têm-se alguns aspectos principais. $\mathrm{O}$ inciso III do art. $1^{\circ}$ da Constituição da República vigente alude ser um

\footnotetext{
${ }^{23}$ Embora Bauman (2001) não concorde com este termo, a passagem desse período se caracteriza como: plural e líquida; onde todas as coisas foram feitas para a temporalidade (efemeridade) e para a fragmentação. $\mathrm{O}$ autor utiliza a fluidez da água como uma metáfora adequada para a Modernidade Líquida - conceito seu sobre esse período.
} 
dos seus fundamentos: "a dignidade da pessoa humana" (BRASIL, 2016, p. 9); já o $§ 7^{\circ}$ do art. 226 ratifica a família protegida pelo Estado por estar fundamentada:

[...] nos princípios da dignidade da pessoa humana e da paternidade responsável, o planejamento familiar é livre decisão do casal, competindo ao Estado propiciar recursos educacionais e científicos para o exercício desse direito, vedada qualquer forma coercitiva por parte de instituições oficiais ou privadas (BRASIL, 2016, p. 68).

Em suma, o Poder Legislativo aduz ao conceito de dignidade humana apenas em abstrato. Este dado, posto dessa forma, criou um ambiente perfeito para a aplicação material da retórica estratégica nas decisões judiciais ${ }^{24}$, porque ninguém em sã consciência irá contra este princípio.

O significante "dignidade da pessoa humana" pode ser visto, então, como um processo de homologização: ele institui poucos pontos de partidas ao mesmo tempo em que alcança uma aderência maior nos contextos eticamente plurais. Sendo assim, a retórica como estudo argumentativo, irá instrumentalizar essa homologização de acordo com o auditório, portanto, caso a caso (DE MARSILLAC, 2017).

\section{DESMANDOS HOMOLÓGICOS DO TOPOS DIGNIDADE DA PESSOA HUMANA NO DIREITO BRASILEIRO}

Com alguns acréscimos a análise de Venceslau Tavares Costa Filho (informação verbal $^{25}$, o presente artigo irá detalhar sobre a decisão judicial proferida em 2015 na 22 Câmara Cível do Tribunal de Justiça do Estado do Rio de Janeiro que julgou a Apelação Cível n o 0019757- 79.2013.8.19.0208 (BRASIL, 2017). Lá se discutia a situação da "cachorrinha

\footnotetext{
${ }^{24} \mathrm{O}$ conceito é considerado pela maioria dos autores como princípio ou valor máximo do ordenamento jurídico. Contudo, sua imprecisão tornou-se um dos problemas centrais na atualidade. Nos assuntos sobre bioética, o termo ganha a roupagem de autonomia da vontade. Em outro momento, o ministro Cezar Peluso utilizou o conceito para emitir improcedência sobre as "brigas de galo", afirmando que esta prática é uma expressão dos impulsos primitivos e irracionais do ser humano (FRIAS; LOPES, 2010).

${ }_{25}$ Análise proferida no 'Curso: Evoluções e Involuções do Direito de Família' realizado através do Instituto Brasiliense de Direito Público| ESMAGIS/TJMT, em Cuiabá, no mês de abril do ano de 2017.
} 
Dully" diante da dissolução da união estável entre seus proprietários. Ao final, decidiu-se por uma posse disfarçada de guarda compartilhada.

O Relator Marcelo Lima Buhatem, de forma infeliz, argumenta sobre a lacuna normativa da seguinte forma: "De fato, cotejado o "ambiente normativo" constata-se que não existe legislação pátria que discipline de modo satisfatório e especifico a questão.” (BRASIL, 2017, p. 206). É necessário observar que este argumento se trata de um erisma ${ }^{26}$.

Segundo Englisch (2001, p. 276), "falaremos em lacuna da lei sempre que desta se não consegue retirar, através da interpretação, qualquer resposta para uma questão jurídica que temos de pôr". A lacuna citada pelo ministro é de lege ferenda e esta não é propriamente uma lacuna normativa na Teoria Geral do Direito, mas uma lacuna político-jurídica.

Englisch (2001, p. 282) ainda observa: "uma lacuna de lege ferenda pode motivar o Poder Legislativo a uma reforma do Direito, mas não o juiz a um preenchimento da dita lacuna". Portanto, o silogismo construído pelo desembargador leva o leitor ao erro de compreensão e a reproduzir uma incoerência sistêmica do fenômeno jurídico.

O instituto da composse (PENTEADO, 2013) poderia ser aplicado ao caso, pois com o fim da comunhão de bens e homologada a separação destes, aquilo que ficar compreendido como sendo indivisível e estando no domínio das duas pessoas torna-se um condomínio. Não havendo assim motivos para o relator criar um "instituto específico" para a decisão sobre a cadela Dully.

Outra questão mal colocada pelo desembargador veio através de um argumento pathos $^{27}$ :

Com efeito, a separação é um momento triste, delicado, dissaboroso, envolvendo sofrimento e rupturas. Em casais jovens ou não, muitas vezes o animal "simboliza" uma espécie de filho, tornando-se, sem nenhum exagero, quase como um ente querido, em torno do qual o casal se une, não somente no que toca ao afeto, mas construindo sobre tal toda uma rotina, uma vida (BRASIL, 2017, p. 205).

\footnotetext{
${ }^{26} \mathrm{O}$ erisma consiste em um silogismo aparente, ou seja, ele se apropria da ignorância das pessoas para estruturar premissas ou conclusões falsas (ADEODATO, 2014).

${ }^{27}$. O ethos, o pathos e o logos são vias clássicas de argumentações adequadas para determinados auditórios sobre algumas circunstâncias. O conceito de pathos significa qualquer emoção, seja de alegria ou dor, para mudar a decisão de um determinado auditório que em seu modo habitual não decidira daquele jeito (ADEODATO, 2010).
} 
Essa opinião apresentada na decisão judicial do relator tentou persuadir as partes do litígio ao raciocínio de que a aproximação afetiva entre os donos com o animal de estimação é equivalente a dos pais em relação aos filhos, legitimando ao caso (Dully) a tutela de possíveis direitos subjetivos (facultas agendi).

Sobre este standard afetivo apresentado anteriormente, vale a reflexão de Tepedino (2016) acerca do dilema afetivo dos modelos familiares. Segundo o autor, o dilema consiste no impasse entre a liberdade/pluralidade familiar e a insuficiência do Legislativo (ou outras fontes do direto estatal) de não estarem prontos para regulamentar as novas relações afetivas.

Entretanto, utilizando-se de uma hermenêutica da desconfiança (COSTA FILHO, 2014), indaga-se: será a relação entre companheiros e um animal de estimação uma entidade familiar para se preocupar com o dilema afetivo? Naturalmente, pelo direito positivo dogmático, o animal de estimação representaria coisa (objeto jurídico tangível da relação entre sujeitos). Contudo, o tratamento dado pelo magistrado foi de uma entidade familiar.

Essa ruptura sistêmica causada pelo ativismo judicial do magistrado é justificada através do $\operatorname{topos}^{28}$ da dignidade da pessoa humana:

Contudo, se o postulado da dignidade da pessoa humana tem ostentado tão multifária
aplicabilidade, espraiando seus efeitos a tantos ramos de direito e "hard cases", não
seria razoável e plausível que, mesmo a despeito de ausência de previsão legal
(somente ainda objeto de projeto de lei) que o julgador propusesse solução à lide,
ainda que intermediária, mas consentânea com o atendimento dos interesses em jogo?
A resposta é claramente positiva, até em homenagem ao princípio que veda o non
liquet, a proibir que se deixe de entregar a jurisdição por obscuridade da demanda ou
norma que lhe discipline. (BRASIL, 2017, p. 206).

Observa-se, portanto, que além do erisma emitido pelo ministro em relação a não disposição normativa sobre o caso, ele também homologiza o princípio da dignidade da pessoa humana com o intuito de julgar a causa de acordo com suas convicções. A constatação dessa má retórica é vista aqui como sendo um reflexo metodológico (solipsista) do "Neoconstitucionalismo" e da "Constitucionalização do Direito Civil".

O Neoconstitucionalismo, como corrente teórica pós-positivista, tenta reaproximar o processo ético (leia-se moral) do direito, além de introduzir ao juiz a estratégia de interpretação

\footnotetext{
${ }^{28}$ São premissas possíveis e igualmente válidas naquele contexto, ou seja, são opiniões aceitáveis entre os juristas para defender um determinado interesse perante um auditório (AMADO, 1999).
} 
por meio da ponderação de princípios. Dessa forma, abandona-se a dogmática jurídica como caricatura do positivismo jurídico e seu método lógico-formal para introduzir em seu lugar um sistema jurídico aberto. Nessa perspectiva, o juiz deve concretizar o direito sempre pelo filtro dos princípios constitucionais (BARROSO, 2001).

A Constitucionalização do Direito Civil, como proposta teórica, vai ao mesmo sentido. A proposta é de intradisciplinaridade, isto é, a dissolução das diferenças entre o direito público e privado para dar lugar a uma hermenêutica unificada. A Constituição, portanto, seria o parâmetro ou centro dos fundamentos da interpretação de todo o sistema jurídico. Assim, a não recepção de alguns artigos ou institutos a partir da publicação da Constituição são inexoráveis para evolução da interpretação e aplicação (LÔBO, 1999).

Segundo Streck (2012), os princípios têm servido como aparato de teorias criadas por juristas práticos para resolverem casos complexos. Têm gerado múltiplos problemas de redundância entre as palavras, termos polissêmicos (alta complexidade) e na sistemática troca da utilização de regras por princípios: sintomas diagnosticados na retórica material efetivada pelo ministro Marcelo Lima Buhatem.

Este pamprincipiologismo (STRECK, 2017) tem recaído no retorno constante aos métodos de completude do direito, mostrando que há uma aparente fragilidade na teorização do ordenamento jurídico. Aproximando-se do caso estudado, o julgamento da ação foi exposto a um arbítrio judicial legitimado por um princípio constitucional e pela justificativa de uma lacuna normativa inexistente, trocando-se uma regra positivada por um princípio totalmente volúvel de significação (de difícil fixação ontológica).

Para mais, deve-se considerar também o abismo hermenêutico existente entre a Constituição e o Código Civil. Segundo Castro Júnior (2011b), a constituição é uma fonte de caráter político-jurídico, e por isso, sua redação se difere das outras legislações, trazendo problemas hermenêuticos a estas (legislações) que foram escritas com um fim (ou tradição) diverso (a).

Essa relação íntima entre a política e o direito (principalmente na fonte constitucional) se dá porque a constituição é justamente o vínculo entre a política e o direito, um acoplamento que deveria ser simétrico e não hierárquico pela composição diferenciada desses subsistemas 
(LEITE, 2008). Contudo, a assimetria e a hierarquização dos acoplamentos sistêmicos são características de como se articula o direito positivado em países periféricos.

Segundo Neves (1996), a desconstitucionalização fática (ou concretização desconstitucionalizante) $)^{29}$ é uma prática recorrente nesses contextos sociais, neles os órgãos estatais e os cidadãos não possuem uma integração com a interpretação/aplicação do texto constitucional. Dessa forma, a autonomia operacional do direito é fraca perante outros subsistemas presentes na sociedade: a política, a economia, a moral e outros.

Dentro desse contexto, se a fonte considerada hierarquicamente maior sofre esta alopoiese ou desmandos do ambiente, quem dirá as fontes infraconstitucionais que são filtradas pela própria constituição? Isto com certeza é um problema metodológico que problematiza a tese da Constitucionalização do Direito Civil. No estudo de caso (Dully), efetivado no presente artigo, uma subsunção clara a um caso fácil foi afastada pelas convicções de um juiz disfarçadas por um princípio constitucional: tratou-se de uma ingerência político-ideológica dentro da seara jurídica.

Essa crítica metodológica a Constitucionalização do Direito Civil (e implicitamente ao Neoconstitucionalismo) é ratificada também por Leal (2015) quando apresenta suas objeções: aumento dos hard cases, carências metodológicas, trivialização da dignidade da pessoa humana e ausência de vinculação ao legislativo.

As carências metodológicas dessas propostas em apresentar métodos de ponderação e interpretação sistemática causam uma visão de que todos os casos são difíceis à dogmática jurídica. Logo, uma "moeda geral” de fácil justificação e significação seria o topos da dignidade da pessoa humana, afastando, então, o trabalho artesanal do jurista procurar por institutos específicos ao caso concreto e construir uma argumentação baseadas em doutrinas jurídicas bem fundamentadas.

\footnotetext{
${ }^{29}$ A Constituição Simbólica é requisito necessário para concretização desconstitucionalizante, isto é, ela possui a função de um topos discursivo político-ideológico que defende: a liberdade, a igualdade etc. Contudo, a sua instrumentalização ou concretização não é proporcional a sua hipertrofia simbólica, servindo a duas funções: não direcionar condutas e orientar expectativas sobre as determinações jurídicas; e responder aos objetivos políticos concretos. Sobre este último, a constituição só seria concretizável se as circunstâncias sociais fossem outras.
} 


\section{CONCLUSÃO}

O ensaio (a pesquisa) sobre a dignidade da pessoa humana teve o intuito de responder se o princípio ou o topos da dignidade da pessoa humana era um juízo legítimo ou um legitimador da ação política dos juízes. Sem dúvida, por mais difícil que seja significar esta expressão, ela tem um papel importante para a democracia e muitas fundamentações de decisões decorrentes desta: união estável entre homossexuais, a antecipação terapêutica do parto no caso dos anencéfalos e outros casos concretos.

Entretanto, como foi visto, a difícil fixação ontológica do significado desse significante revelou a outra face de Janus, mostrando que o uso da dignidade da pessoa humana, enquanto topos argumentativo, está sendo banalizada no direito brasileiro. O custo retórico se torna maior quando a expressão é genérica e abstrata, devendo o retor (jurista) fundamentar bem para que tenha um bom êxito no logos por ele apresentado. Por outro lado, se esta prática não for bem construída, uma análise revelará o mal retórico e consequentemente a face arbitrária daquele que a utiliza.

O julgado da cadela Dully foi um estudo de caso que conseguiu demonstrar bem a prática arbitrária de alguns magistrados brasileiros, transformando suas convicções ideológicas em fundamentos e justificações implícitas nos princípios constitucionais. Esse desenvolvimento "metodológico" está circunscrito em correntes como o Neoconstitucionalismo e a Constitucionalização do Direito Civil, que em vez de trazer mais garantias, abre mais espaço para o arbítrio estatal.

Essas teorias, nada mais são, do que os frutos da crise do classicismo jurídico anunciada por Saldanha (1996). Segundo ele, o contexto de crise do classicismo pelo romantismo jurídico fez a dissolução das codificações e o aumento do poder da Constituição em favor da igualitarização social, já que esta se apresenta como: programa social, valorização do "eu" empírico e representações dos escopos políticos.

Portanto, será o topos da dignidade da pessoa humana a panaceia para todos os problemas jurídico-sociais? Aparentemente não. Tentar "democratizar" (igualitarizar as 
desigualdades) o direito afastando o próprio direito, não é a escolha mais sábia. O direito não está socializado (no sentido de Estado Social), foi apenas tirado de uma casta (legisladores e presidentes) para ser entregue a outra (casta de juízes ou servidores públicos).

Para mais, mesmo que a vinculação a lei (a literalidade jurídica) seja um processo retórico (metafórico), a sua crença é muito funcional na atualidade. A ideia "letra de lei" como correspondência da verdade é um catálogo tópico muito forte no discurso forense (CASTRO JÚNIOR, 2013). Isto força a indagar: será possível um direito (como nós o conhecemos) sem essa suposta literalidade (a retórica da vinculação a lei)?

\section{REFERÊNCIAS BIBLIOGRÁFICAS}

ADEODATO, João Maurício. Ética e retórica: para uma teoria da dogmática jurídica. 4. ed. São Paulo: Saraiva, 2009. 2014.

Uma teoria retórica da norma jurídica e do direito subjetivo. 2. ed. São Paulo: Noeses,

- A retórica constitucional: sobre tolerância, direitos humanos e outros fundamentos éticos do direito. 2. ed. São Paulo: Saraiva, 2010.

AMADO, Juan Antonio García. Retórica, argumentación y derecho. Isegoría, Madrid, n. 21, p. 131-147, 1999.

BARROSO, Luís Roberto. Fundamentos teóricos e filosóficos do novo direito constitucional brasileiro. Revista da EMERJ, Rio de Janeiro, v.4, n.15, p. 11-47, 2001.

BAUMAN, Zygmunt. Modernidade líquida. Trad. Plínio Dentzein. Rio de Janeiro: Jorge Zahar, 2001.

BÍBLIA, A. T. Mateus. In: Português. Sagrada Bíblia. Salt Lake City: A Igreja de Jesus Cristo dos Santos dos Últimos Dias, 2015.

BITTAR, Eduardo Carlos Bianca. ALMEIDA, Guilherme Assis de. Curso de filosofia do direito. 10. ed. São Paulo: Atlas, 2012.

O direito na pós-modernidade e reflexões frankfurtianas. 2. ed. Rio de Janeiro: Forense Universitária, 2009.

BRASIL. Constituição da República Federativa do Brasil. Brasília: Senado Federal, 2016. 
Tribunal de Justiça do Rio de Janeiro. Apelação cível no 0019757-79.2013.8.19.0208 da $22^{\text {a }}$ câmara cível. RBDA, Salvador, v.12, n. 01, p. 201-207, jan./abr., 2017.

CASTRO JÚNIOR., Torquato. Aristóteles e a retórica do saber jurídico. São Paulo: Noeses, 2011a.

Constitucionalização do direito privado e mitologias da legislação: código civil versus constituição. In: STAMFORD DA SILVA, Arthur. $O$ judiciário e o discurso dos direitos humanos. Recife: Ed. Universitária da UFPE, 2011 b.

Metáforas de letras em culturas jurídicas da escrita: como se é fiel à vontade da lei?. Revista Acadêmica, Recife, v. 85, n.2, p. 121-137, 2013.

CHAUÍ, Marilena de Sousa. Convite à filosofia. 14. ed. São Paulo: Ática S.A., 2011.

COSTA FILHO, Venceslau Tavares. Não mencione o código de Napoleão! A análise crítica da pesquisa no ambiente das pós-graduações em direito civil. In: Ruzyk, Carlos Eduardo P. (Org.); Menezes, Joyceane Bezerra de; Ehrhardt Júnior, Marcos. Direito civil constitucional - a ressignificação dos institutos fundamentais do direito civil contemporâneo e sua consequência. Florianópolis: Conselho Editorial, 2014.

CROISSANT, Jeanne. La moralité comme trait distinctif de I'hommedans um texte de Cicéron. Études de philosophie na cienne. Bruxelas: Ousia, 1986, p. 283-296.

DA MAIA, Alexandre. Ontologia jurídica e realidade - o problema da 'Ética da Tolerância'. Revista de Informação Legislativa, Brasília, v. 143, p. 335-345, 1999.

DE MARSILLAC, Narbal. Direitos Humanos e Retórica Pós-Moderna. Revista Brasileira de Direito, Passo Fundo, v. 13, n. 3, p. 318-341, dez. 2017.

ENGISCH, Karl. Introdução ao pensamento jurídico. Trad. João Baptista Machado. Lisboa: Calouste Gulbenkian, 2001.

FALCÃO, Pablo R. de L. Sobre diferentes olhares e percepções ou como revelar o direito através das lentes de sua teoria geral. Revista da Faculdade de Direito de Caruaru, Caruaru, v. 38, p. 243-259, 2007.

FERRARO, Alceu Ravanello. Epistemologia da agroecologia: dialética versus positivismo. Desenvolvimento e Meio Ambiente, Porto Alegre, v. 34, p. 117-134, ago., 2015.

FERRAZ JÚNIOR, Tércio Sampaio. Introdução ao estudo do direito: técnica, decisão, dominação. 6. ed. São Paulo: Atlas, 2012.

. Função social da dogmática jurídica. 2. ed. São Paulo: Atlas, 2015.

FERRY, Luc; JERPHAGON, Lucien. A tentação do cristianismo. Trad. Véra Lúcia dos Reis. Rio de Janeiro: Objetiva, 2011. 
FREITAS, Rita de Cássia Souza Tabosa. O olhar cosmopolita: a atualidade da proposta kantiana para a paz perpétua.2011. 263f. Tese (Doutorado em Filosofia), Programa de Pósgraduação em Filosofia da Universidade da Paraíba, João Pessoa, 2011.

FRIAS, Lincoln; LOPES, Nairo. Considerações sobre o conceito de dignidade humana. Revista GV, São Paulo, v. 11, p. 649-670, 2015.

GERHARDT, Tatiana Engel (Org.); SILVEIRA, Denise Tolfo. Métodos de pesquisa. Porto Alegre: Editora da UFRGS, 2009.

JAPIASSU, Hilton; MARCONDES, Danilo. Dicionário básico de filosofia. 3. ed. Rio de Janeiro: Editora Zahar, 1990.

KANT, Immanuel. A crítica da razão pura. Tradução de Artur Morão. Lisboa: Edições 70, 1994.

LEAL, Fernando. Seis objeções ao direito civil constitucional. Direitos Fundamentais \& Justiça, Porto Alegre, a. 9, n. 33, p. 123-165, out./dez., 2015.

LÔBO, Paulo Luiz Netto. Constitucionalização do direito civil. Revista de Informação Legislativa, Brasília, a. 36, n. 141, jan./mar., 1999.

MATTAR, José Joaquim Marques. A dignidade da pessoa humana como fundamento do estado democrático de direito. Revista Eletrônica de Direito do Estado, Salvador, n. 23, jul-set 2010.

MONSALVE, Viviana Bohórquez. ROMÁN, Javier Aguirre. As tensões da dignidade humana: conceituação e aplicação no direito internacional dos direitos humanos. Revista Internacional de Direitos Humanos, São Paulo, v. 6, n. 11, p. 41-63, dez., 2009.

MOREIRA, Nelson Camatta; MOREIRA JÚNIOR, Ronaldo Felix. Os replicantes de nosso tempo - a violência estatal e a negação da igualdade e dignidade humana a partir da perspectiva da teoria crítica e da distopia na ficção científica. Revista Brasileira de Direito, Passo Fundo, v. 13 , n. 3 , p. $277-294$, dez. 2017

PADILHA, Elisângela; BERTONCINI, Carla. A dignidade da pessoa humana na teoria dos direitos fundamentais de Robert Alexy: uma análise sobre o seu caráter absoluto ou relativo na ordem jurídico-constitucional. Revista Brasileira de Direito, Passo Fundo, v. 12, n. 2, p. 137145, dez. 2016.

PELE, Antonio. La dignidad humana: modelo contemporáneo y modelos tradicionales/A dignidade humana: modelo contemporaneo e modelos tradicionais. Revista Brasileira de Direito, Passo Fundo, v. 11, n. 2, p. 7-17, dez. 2015.

PENTEADO, Luciano de Camargo. Manual de direito civil: coisas. 1. ed. São Paulo: Revista dos Tribunais, 2013.

Referência: REALE, Giovanni; ANTISERI, Dário. História da filosofia: filosofia pagã, v. 1. Tradução de Ivo Storniolo. São Paulo: Paulus, 2003. p. 187-248. 
ROCHA, Leonel Severo. Filosofia analítica e filosofia pragmática. Seqüência, Florianópolis, n. 6, julho, p. 106-109, 1993.

SALDANHA, Nelson. Sobre o "direito civil constitucional". Revista da Faculdade de Direito da UFPR, Curitiba, vol. 36, p. 87-92, 2001.

SANTOS, Boaventura de Sousa. Por uma concepção multicultural dos direitos humanos. Revista Crítica de Ciências Sociais, Coimbra, n. 48, p. 11-32. jun., 1997.

SOARES, Josemar Sidinei; CHIARA LOCCHI, Maria. O papel do indivíduo na construção da dignidade da pessoa humana. Revista Brasileira de Direito, Passo Fundo, v. 12, n. 1, p. 31-41, jun. 2016.

SOBOTA, Katharina. Não mencione a norma. Trad. João Maurício Adeodato. In: Anuário do Mestrado da Faculdade de Direito do Recife, n. 7. Recife: Editora Universitária UFPE, 1996. p. $251-273$

SÓFOCLES.

Antígone.

Disponível

em:

<http://www.ebooksbrasil.org/adobeebook/antigone.pdf>. Acesso em: 6 out 2017.

STRECK, Luiz Lenio. Dicionário de hermenêutica: quarenta temas fundamentais da teoria do direito à luz da crítica hermenêutica do direito. Belo Horizonte: Letramento (Casa do Direito), 2017.

Neoconstitucionalismo, positivismo e pós-positivismo. In: FERRAJOL, Luigi; STRECK, Lênio Luiz; TRINDADE, André Karam. Garantismo, hermenêutica $e$ (neo)constitucionalismo: um debate com Luigi Ferrajoli. Porto Alegre: Livraria do Advogado, 2012.

TEPEDINO, Gustavo. Dilemas do afeto. Revista IBDFAM: Famílias e Sucessões, Belo Horizonte, v. 14, p. 11-27, 2016.

VILLEY, Michel. A formação do pensamento jurídico moderno. Tradução de Claudia Berliner. São Paulo: Martins Fontes, 2005.

Data de Submissão: 02/12/2019

Data de Aceite: 12/12/2019 